\title{
Endoscopic ultrasonography in pancreatic diseases: advances in tissue acquisition
}

\section{(ㄷ)(1) $\Theta$}

Authors

Ioannis V. Mitselos ${ }^{1}$, Ioannis Karoumpalis ${ }^{2}$, Vasileios I. Theopistos ${ }^{1}$, Dimitrios Tzilves ${ }^{3}$, Dimitrios K. Christodoulou ${ }^{1}$

Institutions

1 Department of Gastroenterology, School of Health Sciences, University Hospital of Ioannina, Faculty of Medicine, University of Ioannina, Ioannina, Greece

2 Department of Gastroenterology, General National Hospital of Athens “G. Gennimatas", Athens, Greece

3 Department of Gastroenterology, General Hospital of Thessaloniki “Theageneion”,Thessaloniki, Greece

submitted 19.1.2019

accepted after revision 9.4.2019

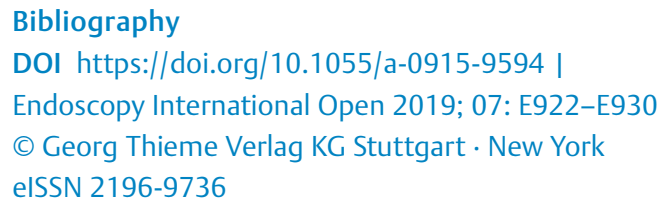

Corresponding author

Dimitrios K. Christodoulou, MD, PhD, University Hospital of Ioannina, Faculty of Medicine, University of Ioannina, PO Box 1186, Ioannina, 45110, Greece

Fax: +30 2651007016

dchristo@uoi.gr

\section{ABSTRACT}

Background and study aims Endoscopic ultrasoundguided fine-needle aspiration (EUS-FNA) improved the diagnostic performance and upgraded the role of endoscopic ultrasonography (EUS) into an interventional modality, able to guide patient management and treatment.This review aimed to highlight the advances, emerging practices, procedural techniques and technological innovations in EUS tissue acquisition in pancreatic diseases.

Methods A thorough review of the literature was performed using PubMed to identify articles that describe techniques, advances, and practices in EUS tissue acquisition in gastrointestinal diseases.

Conclusion Since the first EUS-FNA procedure, EUS guided-tissue acquisition has been evolving continuously. Development of needles with innovative tip design enabled procurement of larger samples with preserved histological architecture. Moreover, sampling techniques and complementary methods, such as contrast harmonic imaging and EUS-elastography, have been introduced in an effort to improve diagnostic performance and sample adequacy.

\section{Introduction}

The innovative combination of ultrasonography and flexible endoscopy resulted in development of endoscopic ultrasound (EUS) [1], which revolutionized our ability to visualize lesions of the gastrointestinal tract, adjacent organs and structures whose assessment was difficult by means of conventional diagnostic modalities and especially transabdominal ultrasound.

EUS was a breakthrough in endoscopic evaluation of benign and malignant diseases, but development of EUS -guided fineneedle Aspiration (EUS-FNA) [2], improved EUS diagnostic performance [3] and upgraded its role into an interventional modality, able to guide patient management and treatment.

Today tissue acquisition is routinely performed during EUS procedures and has been evolving continuously beyond EUSFNA as use of newly developed needles with innovative tip design enables collection of larger tissue samples with preserved histological architecture. Nevertheless, acquisition of adequate tissue samples can be influenced by various factors, such as needle type, geometry, and size; sampling technique; use of needle stylet, use and type of suction, availability of rapid onsite cytopathologist evaluation; sample handling; and endosonographer experience.

This review aimed to highlight the advances, emerging practices, procedural techniques and technological innovations in EUS tissue acquisition in pancreatic diseases.

\section{Literature search}

A thorough review of the literature was performed using PubMed to identify articles that describe techniques, advances, and practices in EUS tissue acquisition in gastrointestinal diseases. 
The search was performed using the search string: ("tissue acquisition" OR "EUS-FNA" OR "EUS-FNB" OR "EUS guided" OR "core tissue" OR "core biopsy" OR "biopsy" OR "biopsies" OR "histology” OR "cytology” OR "microforceps" OR "ProCore” OR "Sharkcore" OR "Acquire") AND ("EUS" OR "endosonography" OR "endoscopic ultrasound"). Only articles in English with relevant titles were reviewed, as well as guidelines and publications from gastroenterological and endoscopic societies regarding EUS procedures and EUS-tissue acquisition.

\section{Needles}

A significant body of literature is available regarding the role of different needle types and needle sizes in diagnostic performance, sample adequacy, and technical difficulties.

A summary of the available needles can be found in $>$ Table 1 .

\section{FNA needles}

Needles primarily designed to collect cells from suspected lesions are known as EUS-FNA needles and information regarding their performance is mainly gained from studies evaluating pancreatic lesions [4]. EUS-FNA needles are characterized by similar safety profiles [5] and are available in 19-, 22 - and 25gauge $(G)$ size.

The smaller 22- and 25-G needles predominantly allow procurement of cytological material, whereas the larger $19 \mathrm{G}$ allows aspiration of both cellular and histological material [4]. However, the inherent rigidity of 19-G EUS-FNA needles results in scope torque, loss of maneuverability, increased rate of technical failure, and limited tissue sample procurement in areas where the echoendoscope is flexed (e.g. pancreatic head, or uncinate process lesions) [6-8]. For these reasons, their use in transduodenal approach is not recommended [4].

Introduction of flexible 19G EUS-FNA needles made of nitinol, a metal alloy of nickel and titanium, exhibiting the properties of shape memory effect and super elasticity, were demonstrated to overcome the aforementioned disadvantages of the standard 19G EUS-FNA needles while allowing acquisition of adequate cytological as well as histological material in the majority of patients (100\% and $94.7 \%$, respectively) [9].

Nevertheless, several meta-analyses investigating the performance of different EUS-FNA needles [6,10-12] reached similar conclusions; in pancreatic and peripancreatic lesions, where cytology is sufficient to reach a diagnosis, $19 \mathrm{G}$ EUS-FNA needles were not demonstrated to confer a diagnostic advantage over the thinner and more commonly used 22 and $25 \mathrm{G}$ needles [13] with respect to diagnostic accuracy, number of passes, and complications. However, in two of the aforementioned meta-analyses, the thinner 25 G EUS-FNA needles demonstrated a marginal advantage regarding sample adequacy [6] and diagnostic sensitivity [11] compared to the $22 \mathrm{G}$ needles.

The diagnostic performance of EUS-FNA is maximized with rapid onsite cytopathology evaluation. When that is not available, cell-block histological sections for off-site cytopathology result in moderate diagnostic accuracy $(75-80 \%)[14,15]$. Moreover, the negative predictive value of EUS-FNA with 22 and $25 \mathrm{G}$ needles was demonstrated to be weak (29.7\% (95\% $\mathrm{Cl} 18.9-42.4 \%)$ vs. $6.9 \%$ [95\% Cl $1.9-16.7 \%$ ], $P=0.001$ ) [16],
- Table 1 Available EUS needles.

\begin{tabular}{|l|l|}
\hline Needle type & Available sizes \\
\hline EUS-FNA & 19, 22, 25-gauge \\
\hline $\begin{array}{l}\text { EchoTip ProCore Needle, Cook Medical, } \\
\text { Indiana, United States }\end{array}$ & $\begin{array}{l}\text { 19, 22, 25-gauge } \\
\text { (Reverse bevel) }\end{array}$ \\
\hline & $\begin{array}{l}\text { 20-gauge } \\
\text { (Antegrade Core Trap) }\end{array}$ \\
\hline $\begin{array}{l}\text { Acquire EUS-FNB Needle, Boston Scientific } \\
\text { Co., Natick, Massachusetts, United States }\end{array}$ & $19,22,25$-gauge \\
\hline $\begin{array}{l}\text { SharkCore EUS-FNB Needle, Medtronic, } \\
\text { Minneapolis, Minnesota, United States }\end{array}$ & $19,22,25$-gauge \\
\hline $\begin{array}{l}\text { EUS-FNA, endoscopic ultrasound-guided fine-needle aspiration; EUS-FNA, } \\
\text { endoscopic ultrasound-guided fine-needle biopsy }\end{array}$ \\
\hline
\end{tabular}

thus, a normal result might not correctly indicate that the patient is disease-free, as the risk of a false negative diagnosis is high.

\section{FNB needles}

While EUS-FNA cytology is suitable for evaluation of pancreatic masses, lymph nodes, and subepithelial tumors, its role is limited in investigation of disorders for which histological samples with preserved tissue architecture are necessary to reach a diagnosis, such as autoimmune pancreatitis [17], lymphomas $[18,19]$, well-differentiated adenocarcinomas, and mesenchymal tumors [20]. Moreover, the yield of true histological samples and quality of the sample material for performance of ancillary testing, for example, identification of specific neoplasmrelated molecular biomarkers, DNA sequencing and characterization of neoplastic features such as desmoplastic fibrosis, was shown to be suboptimal, especially when the smaller 25 G EUSFNA needles were used [21] or when rapid onsite cytopathology evaluation was unavailable $[22,23]$.

The same paradigm was not shown to apply for difficult-touse 19G EUS-FNA needles, as they were demonstrated to provide superior histological yield (>98\%), with excellent sensitivity, specificity, and diagnostic accuracy (91.8\%, 100\%, and $93.2 \%$, respectively) [24]. The first EUS core tissue biopsy needle, the 19G Tru-Cut biopsy needle [25], employed a springloaded mechanism built into the needle handle, which allowed the automatic procurement of true histological samples. However, its use was technically demanding, especially when a transduodenal approach was required [26] and it was linked to increased procedure costs and complication rate [27]. For the aforementioned reasons, use of the 19G Tru-Cut biopsy needle was quickly abandoned.

Needles with hollowed reverse bevel architecture, namely the 19, 22 and 25G EchoTip ProCore (Cook Medical, Indiana, United States) needles, were developed to enable true histological sample procurement.

A significant number of studies investigated performance of the 22 and 25 G ProCore needles in evaluation of solid masses, pancreatic masses, lymph nodes, and subepithelial lesions, 
without being able to firmly establish their superiority with respect to diagnostic accuracy over EUS-FNA needles [28-41].

Similarly, a recent meta-analysis [42] concluded that neither the 19G ProCore needles were able to produce an advantage over EUS-FNA needles, with respect to sample adequacy (75.2\% vs. $89.0 \%$, odds ratio [OR] 0.39, $P=0.23)$, diagnostic accuracy $(85.8 \%$ vs. $86.2 \%$, OR $0.88, P=0.53)$ and core specimen acquisition (77.7\% vs. $76.5 \%$, OR 0.94, $P=0.85$ ). However, ProCore needles were shown to reduce the required number of needle passes compared to EUS-FNA needles, to reach a diagnosis (standardized mean difference $-1.2, P<0.001$ ) [42].

Data evaluating the diagnostic performance of the $20 \mathrm{G}$ ProCore needle, which employs an antegrade core trap instead of reverse bevel architecture, and studies comparing its diagnostic performance against other needles are scarce $[43,44]$.

New EUS-FNB needles with innovative tip geometry, namely the fork-tip (Sharckore; Medtronic, Minneapolis, Minnesota, United States) and Franseen-tip (Acquire, Boston Scientific Co., Natick, Massachusetts, United States) recently have been introduced. The ability of the Acquire needle to procure histological and cytological samples was reported to be superior compared to EUS-FNA needles of the same size (22G) [4547]. Moreover, their high rate of tissue adequacy was not associated with an increase in adverse events [48], despite concerns regarding their use in borderline coagulopathic patients and in pancreatic cyst lesions [49].

Apart from the improved histological yield, both the Franseen-tip and the Fork-tip needle demonstrated excellent diagnostic accuracy (>90\%), with or without presence of rapid onsite evaluation (ROSE) [46]. In addition, they were shown to alleviate the need for ROSE, for both solid pancreatic and nonpancreatic lesions, as well as to reduce the required number of needle passes, with a single pass resulting in an onsite diagnostic accuracy in more than $95 \%$ of patients $[46,47,50-56]$.

Nevertheless, results of a recent meta-analysis could not establish a clear benefit of EUS-FNB over EUS-FNA in the investigation of pancreatic lesions, with regards to diagnostic yield and accuracy [57].

\section{Rapid on-site cytological evaluation}

The rationale behind rapid on-site cytological evaluation of EUS-guided acquired samples is enhancement of sample adequacy and diagnostic yield, with fewer needle passes [58-63]. However, ROSE entails several limitations: it is unavailable in a significant number of institutions due to shortage of experienced pathologists and it results in prolonged procedure duration and increases costs [64]. Meta-analyses based on observational studies resulted in varying results regarding its value in EUS-guided tissue acquisition [65-68], however, the outcome of recent randomized controlled trials indicated that apart from reduction in required needle passes, no benefit could be established regarding diagnostic yield, the proportion of adequate specimens and accuracy in pancreatic masses $[69,70]$. In addition, rapid on-site cytological evaluation during EUS-FNA procedures was not shown to offer a diagnostic advantage over EUS-FNB procedures alone [71-74]. For the aforementioned reasons, use of ROSE could not be rendered mandatory [64].
Table 2 Required needle passes for differentiation of pancreatic lesions.

\begin{tabular}{|l|l|} 
Needle type & $\begin{array}{l}\text { Required needle } \\
\text { passes }\end{array}$ \\
\hline
\end{tabular}

Solid pancreatic masses

\begin{tabular}{|l|c|}
\hline - EUS-FNA & $3-4$ \\
\hline - ProCore & $2-3$ \\
\hline - Franseen-tip \& fork-tip EUS-FNB needles & $1-2$ \\
\hline
\end{tabular}

Pancreatic cystic lesions

- EUS-FNA 1

EUS-FNA, endoscopic ultrasound-guided fine-needle aspiration; EUS-FNS, endoscopic ultrasound-guided fine-needle biopsy

\section{Number of needle passes}

As mentioned above, rapid on-site cytological evaluation is not available in a number of institutions [75]. Thus, a minimum number of needle passes is required to increase the possibility of acquiring adequate samples and reaching accurate diagnoses. Various studies have evaluated the minimum number of required passes [76-79], which is shown to differ between EUSFNA and EUS-FNB procedures.

According to a recently published technical guideline [64], three to four passes with EUS-FNA needles and two to three passes with reverse bevel needles are suggested in diagnostic evaluation of pancreatic masses whereas one EUS-FNA needle pass is adequate for pancreatic cystic lesions. Lymph node investigation with EUS-FNA requires fewer needle passes compared to pancreatic masses, with three needle passes reaching a sensitivity of $100 \%$.

Studies on the recently introduced Franseen-tip and Fork-tip FNB needles indicate that diagnostic adequacy for on-site and off-site evaluation is possible from the first needle pass, for solid mass lesions [50]. A summary of the required needle passes can be found in $>$ Table 2 .

\section{Sampling techniques}

\section{Needle stylet use}

The technique of lesion puncturing without removing the stylet from the needle lumen has been routinely practiced by endosonographers, as it is considered to prevent needle lumen contamination and clogging with unwanted overlaying gastrointestinal tissue [64]. However, various studies were not able to establish a benefit of the aforementioned technique with respect to diagnostic accuracy, adequacy, quality, cellularity or blood contamination on EUS-FNA [80-85] or EUS-FNB procedures [86]. In addition, it was considered labor-intensive and associated with prolonged procedure duration [85-86]. Nevertheless, stylet use may be justified during EUS-FNA investigation of pancreatic cystic lesions, as cystic fluid contamination with gastrointestinal mucin could generate differentiation difficulties [87]. The value of stylet use in EUS procedures with the 
new Franseen-tip and Fork-tip needles remains to be determined.

\section{Dry suction technique}

Sampling under negative pressure, applied with a 10- or 20-cc suction syringe attached to the proximal end port of the needle, is recommended during EUS-FNA of solid masses and lymph nodes [64]. Dry suction increases sample cellularity, diagnostic sensitivity, and diagnostic accuracy, however, it is associated with an increased risk of blood contamination and increased number of needle passes, especially when $22 \mathrm{G}$ needles are used [16].

In addition, dry suction may result in technical failure when smaller needles are used [16]. Use of larger-volume syringes was demonstrated to procure larger samples with an increased risk of blood contamination, however, it was not able to confer an advantage in diagnostic accuracy [88].

\section{Wet suction and modified wet suction technique}

The wet suction technique (WEST) involves replacement of the air column residing inside the EUS-FNA needles, with $5 \mathrm{cc}$ of saline. The rationale behind this technique relies on fluid dynamics. Withdrawal of saline results in negative pressure enhancement at the needle's distal tip, as it is incompressible, as opposed to air [89].

The wet suction technique involves needle flushing with a saline solution before aspiration is performed. Consequently, attachment of a prefilled 10-cc syringe with 3 cc of saline to the needle's proximal end port allows manual intermittent aspiration after the lesion is punctured. This technique was developed [90] to overcome risk of clogging due to blood contamination, associated with the dry suction technique [91, 92].

Although preliminary data on WEST demonstrated superior performance compared to the dry suction technique with respect to sample cellularity and diagnostic yield $[89,90]$, its superiority in diagnostic accuracy is questioned [93, 94]. Recently, a modified (hybrid) version of the wet suction technique (MWST), was introduced $[89,95,96]$. In MWST, needle preparation is identical to the wet suction technique; however, negative pressure is applied continuously through a pre-vacuum syringe. Despite the promising results, further studies are necessary to evaluate its diagnostic advantage on EUS-FNA procedure.

\section{Stylet slow-pull technique}

The stylet slow-pull technique involves needle stylet withdrawal during EUS-FNA, which results in minimum negative pressure generation. It is well known that the dry suction technique may influence the quality of the tissue specimen, mainly by blood contamination. However, the stylet slow-pull technique was associated with improved histological sample quality, reduced blood contamination and similar, or higher, diagnostic performance compared to the dry suction technique [97-100].
- Table 3 Sampling techniques.

Needle stylet use

Dry suction technique

Wet suction and modified wet suction technique

Stylet slow-pull technique

Fanning technique

Through-the-needle biopsy

\section{Fanning technique}

The fanning technique involves sampling multiple areas of the suspected lesion during every needle pass, by changing the needle track with the help of the echoendoscope dials or elevator. The fanning technique was demonstrated to reduce the number of required needle passes to reach a diagnosis without, however, conferring a statistically significant increase in diagnostic accuracy [101].

\section{Through-the-needle biopsy}

EUS-FNA plays a central role in investigation of pancreatic cystic lesions. In particular, use of $19 \mathrm{G}$ or $22 \mathrm{G}$ EUS-FNA needles is the recommended approach [64] for diagnostic evaluation of pancreatic cysts, with or without presence of a solid component. Apart from evaluation of cystic fluid, EUS-FNA allows for cytological and histological evaluation of the pancreatic cystic wall, which was demonstrated to improve diagnostic yield compared with cyst fluid analysis alone [102 - 104].

Development of micro-forceps with an outer diameter of $1 \mathrm{~mm}$ allowed their use through 19G EUS-FNA needles [105], introducing an alternative method for pancreatic cystic wall tissue acquisition. Although available data regarding this innovative technique are limited, results of small studies indicate that it is a promising, highly diagnostic technique, able to determine the nature of pancreatic cysts and guide management, with acceptable rates of technical and clinical success [106-111]. However, the recently published European evidence-based guidelines on pancreatic cystic neoplasms do not recommend use of forceps biopsy in clinical practice due to limited data [112].

A summary of the available sampling techniques can be found in $>$ Table 3 .

\section{Lesion targeting}

Contrast harmonic EUS (CH-EUS) and EUS elastography (EUS-E) were shown to facilitate lesion targeting and puncture site selection during EUS procedures.

\section{Contrast harmonic EUS}

Development of a prototype echo-endoscope [113] equipped with a broadband transducer allowed application of contrast harmonic imaging during EUS procedures. The new transducer offered adequate frequency bandwidth and acoustic power output, enabling detection of harmonic signals from infused ultrasound contrast agents; perfused tissue could be identified as 
an enhanced area, whereas necrotic and fibrotic hypo-perfused regions as hypo-enhanced areas.

The rationale behind its application was that ultrasound contrast agents could facilitate lesion targeting through recognition of parenchymal perfusion and microvasculature disorders, as well as through identification of neoplastic or thrombusrelated vasculature obliteration $[114,115]$. A recent metaanalysis [116] supported the aforementioned hypothesis by demonstrating the superior diagnostic performance of $\mathrm{CH}$-EUS in differential diagnosis of pancreatic masses (sensitivity $94 \%$ [95\% Cl, $0.91-0.95$ ], specificity $89 \%$ [95\% Cl, 0.85-0.92], and area under the curve 0.9732). Moreover, $\mathrm{CH}$-EUS was demonstrated to improve EUS-FNA diagnostic sensitivity in lesions with vascular versus avascular areas (94.3\% vs $72.9 \%$, respectively, $P<0.001)$ [117], as well as to reduce the number of required needle passes to reach a diagnosis [118] and increase tissue adequacy [119]. In addition, CH-EUS was shown to be helpful in investigation of pancreatic cysts for differentiating a mural nodule from mucin and in assessing vascularity within the cyst and septations $[112,120]$.

Nevertheless, histopathology remains the gold-standard for pancreatic cancer diagnosis; $\mathrm{CH}$-EUS should be considered as a complementary tool in evaluation of pancreatic masses, enabling direct lesion targeting [121] until randomized controlled trials provide further evidence of the role of $\mathrm{CH}$-EUS in diagnostic performance and differential diagnosis of pancreatic and non-pancreatic lesions.

\section{EUS elastography}

Elastography provides a qualitative or quantitative evaluation of tissue elasticity in real time. It has been used to investigate benign and malignant lesions, as tissue structure alterations due to neoplasia or inflammation are associated with changes in tissue elasticity. In a recently published prospective study [122], Endoscopic ultrasound elastography (EUS-E) demonstrated high diagnostic accuracy (98.4\%) in evaluation of solid pancreatic masses (95\% confidence interval [Cl]: 91.4-99.7) compared to CEH-EUS and EUS-guided tissue acquisition $85.5 \%$ (95\% Cl: $74.7-92.2)$ and $91.5 \%(95 \% \mathrm{Cl}: 83.6-99.5)$, respectively. However, EUS-E is far from being a substitute for EUSFNA or EUS-FNB procedures in differentiation of pancreatic masses, as several meta-analyses have concluded that despite its high sensitivity (9\%5-99\%), it has moderate specificity $(63 \%-76 \%)$ for diagnosis of pancreatic neoplasia [123-129].

Notwithstanding that, EUS-E is a promising modality in facilitating target selection during EUS-FNA procedures in selected patients with suspected malignant lesions [130]. The combination of $\mathrm{CH}$-EUS with EUS-E was shown to provide complementary information in differential diagnosis of solid pancreatic tumors, however, it results in a non-significant increase in diagnostic accuracy compared to either modality alone [122,131].

\section{Heparin priming}

Blood contamination of the aspirated sample during EUS-FNA procedures may affect sample quality, as formation of blood clots complicates tissue expression, smearing, and microscopic examination $[132,133]$. Moreover, blood clots may complicate stylet reinsertion in the needle lumen [133].

The technique of heparin priming prior to needle puncturing was noted to offer protection against clotting and its effectiveness was evaluated in a small number of studies. It consists of flushing the needle with the heparin solution and reinserting the stylet ("dry heparin" technique), or allowing the heparin solution to remain inside the needle lumen by not reinserting the stylet and applying suction with a pre-vacuum syringe, in a fashion similar to the wet suction technique ("wet heparin" technique) [133].

The wet heparin technique was demonstrated to improve tissue adequacy compared to the dry needle techniques (dry heparin or dry suction technique), in EUS-guided [134] or percutaneous liver biopsy [135]. Nevertheless, in EUS- FNA for pancreatic and other solid lesions, there was no improvement observed with respect to diagnostic performance, tissue adequacy, and median number of passes. Moreover, data regarding its value in blood clotting are conflicting $[132,133]$.

\section{Tissue expression}

Stylet reinsertion is the standard method for EUS-FNA aspirate expression, however, air flushing was demonstrated to be an efficient and safe alternative, able to reduce procedure time, without entailing risk of needle stick injury.

Although both methods resulted in a comparable number of diagnostic samples, diagnostic accuracy, sample cellularity, and air-drying artifact, rates of blood contamination were higher when the stylet reinsertion technique was used [92].

\section{Conclusion}

EUS-FNA improved EUS diagnostic performance; however, the role of FNA cytology in diagnosis of well-differentiated neoplasms as well as its use in ancillary testing is limited, whereas its diagnostic performance is dependent upon, among other things, availability of rapid on-site evaluation. Nineteen-gauge EUS-FNA needles were demonstrated to facilitate procurement of adequate cytological as well as histological material. Nonetheless, their use is associated with an increased rate of technical failure.

Use of reverse-bevel needles was not shown to increase diagnostic accuracy compared to EUS-FNA needles, although a diagnostic sample was feasible with reduced needle passes. Introduction of EUS needles with innovative tip geometry, particularly the Fork-tip and Franseen-tip needles, was expected to revolutionize EUS-guided tissue acquisition. Their design was demonstrated to enable the procurement of true histological samples, resulting in high diagnostic accuracy with a minimum number of needle passes and without the need for rapid onsite evaluation. Another advantage of the Fork-tip and Franseen-tip needles is their superior tissue acquisition yield, which can facilitate ancillary testing such as molecular profiling and immunostaining in cancer patients. However, a clear benefit of EUSFNB over EUS-FNA in investigation of pancreatic lesions, with regards to diagnostic yield and accuracy, is not yet established. 
Dry suction, stylet use, and fanning technique were not shown to firmly establish an advantage during EUS-FNA procedures. On the contrary, application of ultrasound contrast agents or elastography during EUS procedures are promising, innovative, and complementary modalities that were shown to improve lesion targeting and puncture site selection.

Despite the promising future, current procedure practices appear to be dictated by needle availability and cost, lesion location and type, need to preserve tissue architecture to reach a diagnosis, and endosonographer's experience and preferences.

\section{Competing interests}

None

\section{References}

[1] DiMagno EP, Buxton JL, Regan PT et al. Ultrasonic endoscope. Lancet 1980; 1: 629-631

[2] Vilmann P, Jacobsen GK, Henriksen FW et al. Endoscopic ultrasonography with guided fine needle aspiration biopsy in pancreatic disease. Gastrointest Endosc 1992; 38: $172-173$

[3] Puli SR, Batapati Krishna Reddy J, Bechtold ML et al. Endoscopic ultrasound: it's accuracy in evaluating mediastinal lymphadenopathy? A meta-analysis and systematic review. World J Gastroenterol 2008; 14: $3028-3037$

[4] Polkowski M, Larghi A, Weynand B et al. Learning, techniques, and complications of endoscopic ultrasound (EUS)-guided sampling in gastroenterology: European Society of Gastrointestinal Endoscopy (ESGE) Technical Guideline. Endoscopy 2012; 44: 190 - 206

[5] Lancelot R, Gonzalez JP, Le Guenno B et al. Descriptive epidemiology of Rift Valley fever in small ruminants in Southern Mauritania after the 1988 rainy season. Rev Elev Med Vet Pays Trop 1990; 42: 485 491

[6] Affolter KE, Schmidt RL, Matynia AP et al. Needle size has only a limited effect on outcomes in EUS-guided fine needle aspiration: a systematic review and meta-analysis. Dig Dis Sci 2013; 58: 1026-1034

[7] Vilmann P, Seicean A, Saftoiu A. Tips to overcome technical challenges in EUS-guided tissue acquisition. Gastrointest Endosc Clin N Am 2014; 24: 109-124

[8] Song T], Kim JH, Lee SS et al. The prospective randomized, controlled trial of endoscopic ultrasound-guided fine-needle aspiration using 22G and 19G aspiration needles for solid pancreatic or peripancreatic masses. Am J Gastroenterol 2010; 105: 1739-1745

[9] Varadarajulu S, Bang JY, Hebert-Magee S. Assessment of the technical performance of the flexible 19-gauge EUS-FNA needle. Gastrointest Endosc 2012; 76: 336-343

[10] Facciorusso A, Stasi E, Di Maso M et al. Endoscopic ultrasound-guided fine needle aspiration of pancreatic lesions with 22 versus 25 gauge needles: A meta-analysis. United European Gastroenterol J 2017; 5: $846-853$

[11] Xu MM, Jia HY, Yan LL et al. Comparison of two different size needles in endoscopic ultrasound-guided fine-needle aspiration for diagnosing solid pancreatic lesions: A meta-analysis of prospective controlled trials. Medicine (Baltimore) 2017; 96: e5802

[12] Madhoun MF, Wani SB, Rastogi A et al. The diagnostic accuracy of 22-gauge and 25-gauge needles in endoscopic ultrasound-guided fine needle aspiration of solid pancreatic lesions: a meta-analysis. Endoscopy 2013; 45: 86-92
[13] Muniraj T, Aslanian HR. New Developments in endoscopic ultrasound tissue acquisition. Gastrointest Endosc Clin N Am 2017; 27: 585-599

[14] Kopelman Y, Marmor S, Ashkenazi I et al. Value of EUS-FNA cytological preparations compared with cell block sections in the diagnosis of pancreatic solid tumours. Cytopathology 2011; 22: 174-178

[15] Varadarajulu S, Bang JY, Holt BA et al. The 25-gauge EUS-FNA needle: Good for on-site but poor for off-site evaluation? Results of a randomized trial Gastrointest Endosc 2014; 80: 1056-1063

[16] Bang JY, Navaneethan U, Hasan MK et al. Endoscopic ultrasoundguided specimen collection and evaluation techniques affect diagnostic accuracy. Clin Gastroenterol Hepatol 2018; 16: 1820-1828

[17] Kamisawa T, Ohara H, Kim MH et al. Role of endoscopy in the diagnosis of autoimmune pancreatitis and immunoglobulin G4-related sclerosing cholangitis. Dig Endosc 2014; 26: 627-635

[18] Eloubeidi MA, Mehra M, Bean SM. EUS-guided 19-gauge trucut needle biopsy for diagnosis of lymphoma missed by EUS-guided FNA. Gastrointest Endosc 2007; 65: 937-939

[19] Guo J, Sun B, Wang S et al. Diagnosis of lymphoma by endoscopic ultrasound-assisted transendoscopic direct retroperitoneal lymph node biopsy: A case report (with video). Endosc Ultrasound 2015; 4: $69-72$

[20] Karadsheh Z, Al-Haddad M. Endoscopic ultrasound guided fine needle tissue acquisition: where we stand in 2013? World J Gastroenterol 2014; 20: $2176-2185$

[21] Sakamoto H, Kitano M, Komaki T et al. Prospective comparative study of the EUS guided 25-gauge FNA needle with the 19-gauge Trucut needle and 22-gauge FNA needle in patients with solid pancreatic masses. J Gastroenterol Hepatol 2009; 24: 384-390

[22] da Cunha SantosG. ROSEs (Rapid on-site evaluations) to our patients: The impact on laboratory resources and patient care. Cancer Cytopathol 2013; 121: 537-539

[23] Knoepp SM, Roh MH. Ancillary techniques on direct-smear aspirate slides: a significant evolution for cytopathology techniques. Cancer Cytopathol 2013; 121: 120-128

[24] Larghi A, Verna EC, Ricci R et al. EUS-guided fine-needle tissue acquisition by using a 19-gauge needle in a selected patient population: a prospective study. Gastrointest Endosc 2011; 74: 504-510

[25] Levy MJ, Jondal ML, Clain J et al. Preliminary experience with an EUSguided trucut biopsy needle compared with EUS-guided FNA. Gastrointest Endosc 2003; 57: $101-106$

[26] Larghi A, Verna EC, Stavropoulos SN et al. EUS-guided trucut needle biopsies in patients with solid pancreatic masses: a prospective study. Gastrointest Endosc 2004; 59: 185-190

[27] Levy M], Wiersema M]. EUS-guided Trucut biopsy. Gastrointest Endosc 2005; 62: 417-426

[28] Othman MO, Abdelfatah MM, Padilla O et al. The cellularity yield of three different 22-gauge endoscopic ultrasound fine needle aspiration needles. Diagn Cytopathol 2017; 45: 426-432

[29] Lee BS, Cho CM, Jung MK et al. Comparison of histologic core portions acquired from a core biopsy needle and a conventional needle in solid mass lesions: a prospective randomized trial. Gut Liver 2017; 11: $559-566$

[30] Han JP, Lee TH, Hong S] et al. EUS-guided FNA and FNB after on-site cytological evaluation in gastric subepithelial tumors. J Dig Dis 2016; 17: $582-587$

[31] Sterlacci W, Sioulas AD, Veits L et al. 22-gauge core vs 22-gauge aspiration needle for endoscopic ultrasound-guided sampling of abdominal masses. World J Gastroenterol 2016; 22: 8820-8830

[32] Vanbiervliet G, Napoleon B, Saint Paul MC et al. Core needle versus standard needle for endoscopic ultrasound-guided biopsy of solid pancreatic masses: a randomized crossover study. Endoscopy 2014; 46: $1063-1070$ 
[33] Kim GH, Cho YK, Kim EY et al. Comparison of 22-gauge aspiration needle with 22-gauge biopsy needle in endoscopic ultrasonographyguided subepithelial tumor sampling. Scand J Gastroenterol 2014; 49: $347-354$

[34] Hucl T, Wee E, Anuradha $S$ et al. Feasibility and efficiency of a new $22 \mathrm{G}$ core needle: a prospective comparison study. Endoscopy 2013; 45: $792-798$

[35] Bang JY, Hebert-Magee S, Trevino J et al. Randomized trial comparing the 22-gauge aspiration and 22-gauge biopsy needles for EUSguided sampling of solid pancreatic mass lesions. Gastrointest Endosc 2012; 76: $321-327$

[36] Lee YN, Moon JH, Kim HK et al. Core biopsy needle versus standard aspiration needle for endoscopic ultrasound-guided sampling of solid pancreatic masses: a randomized parallel-group study. Endoscopy 2014; 46: $1056-1062$

[37] Alatawi A, Beuvon F, Grabar S et al. Comparison of 22G reverse-beveled versus standard needle for endoscopic ultrasound-guided sampling of solid pancreatic lesions. United European Gastroenterol J 2015; $3: 343-352$

[38] Kamata K, Kitano M, Yasukawa S et al. Histologic diagnosis of pancreatic masses using 25-gauge endoscopic ultrasound needles with and without a core trap: a multicenter randomized trial. Endoscopy 2016; 48: $632-638$

[39] Strand DS, Jeffus SK, Sauer BG et al. EUS-guided 22-gauge fine-needle aspiration versus core biopsy needle in the evaluation of solid pancreatic neoplasms. Diagn Cytopathol 2014; 42: 751 -758

[40] Witt BL, Adler DG, Hilden K et al. A comparative needle study: EUSFNA procedures using the HD ProCore() and EchoTip((R)) 22-gauge needle types. Diagn Cytopathol 2013; 41: 1069-1074

[41] Chong CCN, Teoh AYB, Tang RSY et al. EUS-FNA using 22G nitinol or ProCore needles without on-site cytopathology. Endosc Ultrasound 2018; 7: $56-60$

[42] Bang JY, Hawes R, Varadarajulu S. A meta-analysis comparing ProCore and standard fine-needle aspiration needles for endoscopic ultrasound-guided tissue acquisition. Endoscopy 2016; 48: 339-349

[43] Antonini F, Delconte G, Fuccio L et al. EUS-guided tissue sampling with a 20-gauge core biopsy needle for the characterization of gastrointestinal subepithelial lesions: A multicenter study. Endosc UItrasound 2018; 8: 105-110

[44] van Riet PA, Larghi A, Attili F et al. A multicenter randomized trial comparing a 25-gauge EUS fine-needle aspiration device with a 20gauge EUS fine-needle biopsy device. Gastrointest Endosc 2019; 89: 329- 339

[45] Bang JY, Hebert-Magee S, Navaneethan U et al. EUS-guided fine needle biopsy of pancreatic masses can yield true histology: results of a randomised trial. Gut 2018; 67: 2081-2084

[46] Bang JY, Hebert-Magee S, Navaneethan $U$ et al. Randomized trial comparing the Franseen and Fork-tip needles for EUS-guided fineneedle biopsy sampling of solid pancreatic mass lesions. Gastrointest Endosc 2018; 87: 1432 - 1438

[47] El Hajj II, Wu H, Reuss S et al. Prospective assessment of the performance of a new fine needle biopsy device for EUS-guided sampling of solid lesions. Clin Endosc 2018; 51: 576- 583

[48] Adler DG, Muthusamy VR, Ehrlich DS et al. A multicenter evaluation of a new EUS core biopsy needle: Experience in 200 patients. Endosc Ultrasound 2019; 8: 99-104

[49] Bang JY, Varadarajulu S. Reply. Clin Gastroenterol Hepatol 2018; 16 : 1362

[50] Bang JY, Kirtane S, Krall K et al. In memoriam - fine needle aspiration, Birth - fine needle biopsy:The changing trend in endoscopic ultrasound-guided tissue acquisition. Dig Endosc 2019; 31: 197-202
[51] Lee W], Uradomo LT, Zhang Y et al. Comparison of the diagnostic yield of EUS needles for liver biopsy: ex vivo study. Diagn Ther Endosc 2017; 2017: 1497831

[52] Witt BL, Factor RE, Chadwick BE et al. Evaluation of the SharkCore ${ }^{\circledR}$ needle for EUS-guided core biopsy of pancreatic neuroendocrine tumors. Endosc Ultrasound 2018; 7: 323-328

[53] Mukai S, Itoi T, Yamaguchi H et al. A retrospective histological comparison of EUS-guided fine-needle biopsy using a novel franseen needle and a conventional end-cut type needle. Endosc Ultrasound 2019; 8: 50 - 57

[54] Naveed M, Siddiqui AA, Kowalski TE et al. A Multicenter comparative trial of a novel EUS-guided core biopsy needle (SharkCore ${ }^{\mathrm{TM}}$ ) with the 22-gauge needle in patients with solid pancreatic mass lesions. Endosc Ultrasound 2018; 7: 34-40

[55] Larsen MH, Fristrup CW, Detlefsen S et al. Prospective evaluation of EUS-guided fine needle biopsy in pancreatic mass lesions. Endosc Int Open 2018; 6: E242-E248

[56] Bhattacharya A, Cruise M, Chahal P. Endoscopic ultrasound guided 22 gauge core needle biopsy for the diagnosis of Autoimmune pancreatitis. Pancreatology 2018; 18: 168-169

[57] Machicado JD, Thosani N, Wani S. Will abandoning fine-needle aspiration increase diagnostic yield from tissues collected during endoscopic ultrasound? Clin Gastroenterol Hepatol 2018; 16: $1203-1206$

[58] Koul A, Baxi AC, Shang R et al. The efficacy of rapid on-site evaluation during endoscopic ultrasound-guided fine needle aspiration of pancreatic masses. Gastroenterol Rep (Oxf) 2018; 6: 45 - 48

[59] Mohanty SK, Pradhan D, Sharma S et al. Endoscopic ultrasound guided fine-needle aspiration: What variables influence diagnostic yield? Diagn Cytopathol 2018; 46: 293 - 298

[60] Tamura T, Yamashita Y, Ueda K et al. Rapid on-site evaluation by endosonographers during endoscopic ultrasonography-guided fineneedle aspiration for diagnosis of gastrointestinal stromal tumors. Clin Endosc 2017: 50: 372-378

[61] Ganc RL, Carbonari AP, Colaiacovo R et al. Rapid on-site cytopathological examination (ROSE) performed by endosonagraphers and its improvement in the diagnosis of pancreatic solid lesions. Acta Cir Bras 2015; 30: $503-508$

[62] Schmidt RL, Witt BL, Matynia AP et al. Rapid on-site evaluation increases endoscopic ultrasound-guided fine-needle aspiration adequacy for pancreatic lesions. Dig Dis Sci 2013; 58: 872 - 882

[63] Iglesias-Garcia J, Dominguez-Munoz JE, Abdulkader I et al. Influence of on-site cytopathology evaluation on the diagnostic accuracy of endoscopic ultrasound-guided fine needle aspiration (EUS-FNA) of solid pancreatic masses. Am J Gastroenterol 2011; 106: 1705-1710

[64] Polkowski M, Jenssen C, Kaye P et al. Technical aspects of endoscopic ultrasound (EUS)-guided sampling in gastroenterology: European Society of Gastrointestinal Endoscopy (ESGE) Technical Guideline March 2017. Endoscopy 2017; 49: 989-1006

[65] Hebert-Magee S, Bae S, Varadarajulu S et al. The presence of a cytopathologist increases the diagnostic accuracy of endoscopic ultrasound-guided fine needle aspiration cytology for pancreatic adenocarcinoma: a meta-analysis. Cytopathology 2013; 24: 159-171

[66] Matynia AP, Schmidt RL, Barraza G et al. Impact of rapid on-site evaluation on the adequacy of endoscopic-ultrasound guided fineneedle aspiration of solid pancreatic lesions: a systematic review and meta-analysis. J Gastroenterol Hepatol 2014; 29: 697-705

[67] Kong F, Zhu J, Kong X et al. Rapid on-site evaluation does not improve endoscopic ultrasound-guided fine needle aspiration adequacy in pancreatic masses: a meta-analysis and systematic review. PLoS One 2016; 11: e0163056

[68] Hewitt MJ, McPhail MJ, Possamai L et al. EUS-guided FNA for diagnosis of solid pancreatic neoplasms: a meta-analysis. Gastrointest Endosc 2012; 75: 319-331 
[69] Wani S, Mullady D, Early DS et al. The clinical impact of immediate on-site cytopathology evaluation during endoscopic ultrasoundguided fine needle aspiration of pancreatic masses: a prospective multicenter randomized controlled trial. Am J Gastroenterol 2015; 110: $1429-1439$

[70] Lee LS, Nieto J, Watson RR et al. Randomized noninferiority trial comparing diagnostic yield of cytopathologist-guided versus 7 passes for EUS-FNA of pancreatic masses. Dig Endosc 2016; 28: $469-$ 475

[71] Arena M, Eusebi LH, Pellicano R et al. Endoscopic ultrasound core needle for diagnosing of solid pancreatic lesions: is rapid on-site evaluation really necessary? Minerva Med 2017; 108: 547-553

[72] Fabbri C, Fuccio L, Fornelli A et al. The presence of rapid on-site evaluation did not increase the adequacy and diagnostic accuracy of endoscopic ultrasound-guided tissue acquisition of solid pancreatic lesions with core needle. Surg Endosc 2017; 31: 225 - 230

[73] Lin M, Hair CD, Green LK et al. Endoscopic ultrasound-guided fineneedle aspiration with on-site cytopathology versus core biopsy: a comparison of both techniques performed at the same endoscopic session. Endosc Int Open 2014; 2: E220 - 223

[74] Keswani RN, Krishnan K, Wani S et al. Addition of endoscopic ultrasound (EUS)-guided fine needle aspiration and on-site cytology to EUS-guided fine needle biopsy increases procedure time but not diagnostic accuracy. Clin Endosc 2014; 47: 242 - 247

[75] van Riet PA, Cahen DL, Poley JW et al. Mapping international practice patterns in EUS-guided tissue sampling: outcome of a global survey. Endosc Int Open 2016; 4: E360 - 370

[76] Uehara H, Sueyoshi H, Takada R et al. Optimal number of needle passes in endoscopic ultrasound-guided fine needle aspiration for pancreatic lesions. Pancreatology 2015; 15: $392-396$

[77] Erickson RA, Sayage-Rabie L, Beissner RS. Factors predicting the number of EUS-guided fine-needle passes for diagnosis of pancreatic malignancies. Gastrointest Endosc 2000; 51: 184-190

[78] LeBlanc JK, Ciaccia D, Al-Assi MT et al. Optimal number of EUS-guided fine needle passes needed to obtain a correct diagnosis. Gastrointest Endosc 2004; 59: 475-481

[79] Mohamadnejad M, Mullady D, Early DS et al. Increasing number of passes beyond 4 does not increase sensitivity of detection of pancreatic malignancy by endoscopic ultrasound-guided fine-needle aspiration. Clin Gastroenterol Hepatol 2017; 15: 1071 - 1078 e1072

[80] Abe Y, Kawakami H, Oba K et al. Effect of a stylet on a histological specimen in EUS-guided fine-needle tissue acquisition by using 22gauge needles: a multicenter, prospective, randomized, controlled trial. Gastrointest Endosc 2015; 82: 837 - 844 e831

[81] Wani S, Early D, Kunkel J et al. Diagnostic yield of malignancy during EUS-guided FNA of solid lesions with and without a stylet: a prospective, single blind, randomized, controlled trial. Gastrointest Endosc 2012; 76: $328-335$

[82] Rastogi A, Wani S, Gupta N et al. A prospective, single-blind, randomized, controlled trial of EUS-guided FNA with and without a stylet. Gastrointest Endosc 2011; 74: 58-64

[83] Lai A, Davis-Yadley A, Lipka S et al. the use of a stylet in endoscopic ultrasound with fine-needle aspiration: a systematic review and meta-analysis. J Clin Gastroenterol 2019; 53: 1-8

[84] Kim JH, Park SW, Kim MK et al. Meta-Analysis for Cyto-Pathological Outcomes in Endoscopic Ultrasonography-Guided Fine-Needle Aspiration With and Without the Stylet. Dig Dis Sci 2016; 61: 2175 2184

[85] Wani S, Gupta N, Gaddam S et al. A comparative study of endoscopic ultrasound guided fine needle aspiration with and without a stylet. Dig Dis Sci 2011; 56: 2409-2414

[86] Yang MJ, Hwang JC, Yoo BM et al. A prospective randomized trial of EUS-guided tissue acquisition using a 25-gauge core biopsy needle with and without a stylet. Surg Endosc 2018; 32: 3777-3782
[87] Cazacu IM, Luzuriaga Chavez AA, Saftoiu A et al. A quarter century of EUS-FNA: Progress, milestones, and future directions. Endosc Ultrasound 2018; 7: $141-160$

[88] Kudo T, Kawakami H, Hayashi T et al. High and low negative pressure suction techniques in EUS-guided fine-needle tissue acquisition by using 25-gauge needles: a multicenter, prospective, randomized, controlled trial. Gastrointest Endosc 2014; 80: 1030-1037 e1031

[89] Villa NA, Berzosa M, Wallace MB et al. Endoscopic ultrasound-guided fine needle aspiration: The wet suction technique. Endosc Ultrasound 2016; 5: 17-20

[90] Attam R, Arain MA, Bloechl S] et al. "Wet suction technique (WEST)": a novel way to enhance the quality of EUS-FNA aspirate. Results of a prospective, single-blind, randomized, controlled trial using a 22gauge needle for EUS-FNA of solid lesions. Gastrointest Endosc 2015; 81: $1401-1407$

[91] Wallace MB, Kennedy T, Durkalski V et al. Randomized controlled trial of EUS-guided fine needle aspiration techniques for the detection of malignant lymphadenopathy. Gastrointest Endosc 2001; 54: $441-447$

[92] Lee JK, Choi JH, Lee KH et al. A prospective, comparative trial to optimize sampling techniques in EUS-guided FNA of solid pancreatic masses. Gastrointest Endosc 2013; 77: 745-751

[93] Wang R, Wang J, Li Y et al. Diagnostic accuracies of endoscopic ultrasound-guided fine-needle aspiration with distinct negative pressure suction techniques in solid lesions: A retrospective study. Onco Lett 2017; 13: 3709-3716

[94] Antonini F, Fuccio L, Fabbri C et al. Endoscopic ultrasound-guided tissue acquisition of pancreatic masses with core biopsy needles using wet suction technique. Endoscopic Ultrasound 2017; 6: 73 74

[95] Berzosa M, Villa N, Bartel M] et al. Mo1420 pilot study comparing hybrid vs. wet vs. dry suction techniques for EUS-FNA of solid lesions. Gastrointest Endosc 2014; 79: AB430

[96] Wang Y, Chen Q, Wang J et al. Comparison of modified wet suction technique and dry suction technique in endoscopic ultrasoundguided fine-needle aspiration (EUS-FNA) for solid lesions: study protocol for a randomized controlled trial. Trials 2018; 19: 45

[97] Saxena P, El Zein M, Stevens T et al. Stylet slow-pull versus standard suction for endoscopic ultrasound-guided fine-needle aspiration of solid pancreatic lesions: a multicenter randomized trial. Endoscopy 2018; 50: 497-504

[98] Chen JY, Ding QY, Lv Y et al. Slow-pull and different conventional suction techniques in endoscopic ultrasound-guided fine-needle aspiration of pancreatic solid lesions using 22-gauge needles. World J Gastroenterol 2016; 22: 8790-8797

[99] Nakai $\mathrm{Y}$, Isayama H, Chang KJ et al. Slow pull versus suction in endoscopic ultrasound-guided fine-needle aspiration of pancreatic solid masses. Dig Dis Sci 2014; 59: 1578-1585

[100] El Haddad R, Barret M, Beuvon F et al. The slow-pull capillary technique increases the quality of endoscopic ultrasound fine needle biopsy samples in solid pancreatic lesions. Eur J Gastroenterol Hepatol 2016; 28: $911-916$

[101] Bang JY, Magee SH, Ramesh J et al. Randomized trial comparing fanning with standard technique for endoscopic ultrasound-guided fine-needle aspiration of solid pancreatic mass lesions. Endoscopy 2013; 45: 445-450

[102] Barresi L, Tarantino I, Traina M et al. Endoscopic ultrasound-guided fine needle aspiration and biopsy using a 22-gauge needle with side fenestration in pancreatic cystic lesions. Dig Liver Dis 2014; 46: 45 50

[103] Hong SK, Loren DE, Rogart JN et al. Targeted cyst wall puncture and aspiration during EUS-FNA increases the diagnostic yield of premalignant and malignant pancreatic cysts. Gastrointest Endosc 2012; 75: $775-782$ 
[104] Rogart JN, Loren DE, Singu BS et al. Cyst wall puncture and aspiration during EUS-guided fine needle aspiration may increase the diagnostic yield of mucinous cysts of the pancreas. J Clin Gastroenterol 2011; 45: $164-169$

[105] Samarasena JB, Nakai Y, Shinoura S et al. EUS-guided, through-theneedle forceps biopsy: a novel tissue acquisition technique. Gastrointest Endosc 2015; 81: 225-226

[106] Kovacevic B, Karstensen JG, Havre RF et al. Initial experience with EUS-guided microbiopsy forceps in diagnosing pancreatic cystic lesions: A multicenter feasibility study (with video). Endosc Ultrasound 2018; 7: $383-388$

[107] Kovacevic B, Klausen P, Hasselby JP et al. A novel endoscopic ultrasound-guided through-the-needle microbiopsy procedure improves diagnosis of pancreatic cystic lesions. Endoscopy 2018; 50: 1105 1111

[108] Nakai Y, Isayama H, Chang KJ et al. A pilot study of EUS-guided through-the-needle forceps biopsy (with video). Gastrointest Endosc 2016; 84: $158-162$

[109] Basar O, Yuksel O, Yang DJ et al. Feasibility and safety of microforceps biopsy in the diagnosis of pancreatic cysts. Gastrointest Endosc 2018; 88: 79-86

[110] Shakhatreh MH, Naini SR, Brijbassie AA et al. Use of a novel throughthe-needle biopsy forceps in endoscopic ultrasound. Endosc Int Open 2016; 4: E439-442

[111] Barresi L, Crino SF, Fabbri C et al. Endoscopic ultrasound-throughthe-needle biopsy in pancreatic cystic lesions: A multicenter study. Dig Endosc 2018; 30: 760 - 770

[112] European Study Group on Cystic Tumours of the P. European evidence-based guidelines on pancreatic cystic neoplasms. Gut 2018; 67: $789-804$

[113] Kitano M, Kudo M, Sakamoto $\mathrm{H}$ et al. Preliminary study of contrastenhanced harmonic endosonography with second-generation contrast agents. J Med Ultrason (2001) 2008; 35: 11-18

[114] Kitano M, Sakamoto H, Matsui U et al. A novel perfusion imaging technique of the pancreas: contrast-enhanced harmonic EUS (with video). Gastrointest Endosc 2008; 67: 141-150

[115] Yoo ], Yan LH, Siddiqui AA. Can contrast harmonic endoscopic ultrasonography replace endoscopic ultrasonography-guided fine-needle aspiration in patients with solid pancreatic lesions? An American perspective. Endosc Ultrasound 2017; 6: 1-3

[116] Gong TT, Hu DM, Zhu Q. Contrast-enhanced EUS for differential diagnosis of pancreatic mass lesions: a meta-analysis. Gastrointest Endosc 2012; 76: 301 - 309

[117] Kamata K, Takenaka M, Omoto $S$ et al. Impact of avascular areas, as measured by contrast-enhanced harmonic EUS, on the accuracy of FNA for pancreatic adenocarcinoma. Gastrointest Endosc 2018; 87: $158-163$

[118] Sugimoto M, Takagi T, Hikichi T et al. Conventional versus contrastenhanced harmonic endoscopic ultrasonography-guided fine-needle aspiration for diagnosis of solid pancreatic lesions: A prospective randomized trial. Pancreatology 2015; 15: 538 - 541

[119] Hou X, Jin Z, Xu C et al. Contrast-enhanced harmonic endoscopic ultrasound-guided fine-needle aspiration in the diagnosis of solid pancreatic lesions: a retrospective study. PLoS One 2015; 10 : e0121236
[120] Kamata K, Kitano M, Omoto S et al. Contrast-enhanced harmonic endoscopic ultrasonography for differential diagnosis of pancreatic cysts. Endoscopy 2016; 48: 35-41

[121] Ryozawa S, Kitoh H, Gondo T et al. Usefulness of endoscopic ultrasound-guided fine-needle aspiration biopsy for the diagnosis of pancreatic cancer. J Gastroenterol 2005; 40: 907-911

[122] Iglesias-Garcia J, Lindkvist B, Larino-Noia J et al. Differential diagnosis of solid pancreatic masses: contrast-enhanced harmonic (CEHEUS), quantitative-elastography (QE-EUS), or both? United European Gastroenterol J 2017; 5: 236-246

[123] Pei Q, Zou X, Zhang X et al. Diagnostic value of EUS elastography in differentiation of benign and malignant solid pancreatic masses: a meta-analysis. Pancreatology 2012; 12: $402-408$

[124] Hu DM, Gong TT, Zhu Q. Endoscopic ultrasound elastography for differential diagnosis of pancreatic masses: a meta-analysis. Dig Dis Sci 2013; 58: $1125-1131$

[125] Li X, Xu W, Shi ] et al. Endoscopic ultrasound elastography for differentiating between pancreatic adenocarcinoma and inflammatory masses: a meta-analysis. World J Gastroenterol 2013; 19: 6284 6291

[126] Mei M, Ni J, Liu D et al. EUS elastography for diagnosis of solid pancreatic masses: a meta-analysis. Gastrointest Endosc 2013; 77: $578-589$

[127] Xu W, Shi ], Li X et al. Endoscopic ultrasound elastography for differentiation of benign and malignant pancreatic masses: a systemic review and meta-analysis. Eur J Gastroenterol Hepatol 2013; 25: $218-224$

[128] Ying L, Lin X, Xie ZL et al. Clinical utility of endoscopic ultrasound elastography for identification of malignant pancreatic masses: a meta-analysis. J Gastroenterol Hepatol 2013; 28: 1434-1443

[129] Zhang B, Zhu F, Li P et al. Endoscopic ultrasound elastography in the diagnosis of pancreatic masses: A meta-analysis. Pancreatology 2018; 18: $833-840$

[130] Jafri M, Sachdev AH, Khanna L et al. The role of real time endoscopic ultrasound guided elastography for targeting EUS-FNA of suspicious pancreatic masses: a review of the literature and a single center experience. JOP 2016; 17: 516-524

[131] Chantarojanasiri T, Hirooka Y, Kawashima H et al. Endoscopic ultrasound in diagnosis of solid pancreatic lesions: Elastography or contrast-enhanced harmonic alone versus the combination. Endosc Int Open 2017; 5: E1136-E1143

[132] Hasan MK, Bang JY, Varadarajulu S. Diagnostic value of priming the endoscopic ultrasound-guided fine-needle aspiration needle with heparin to improve specimen quality. Dig Endosc 2014; 26: 491

[133] Diehl DL, Mok SRS, Khara HS et al. Heparin priming of EUS-FNA needles does not adversely affect tissue cytology or immunohistochemical staining. Endosc Int Open 2018; 6: E356-E362

[134] Mok SRS, Diehl DL, Johal AS et al. A prospective pilot comparison of wet and dry heparinized suction for EUS-guided liver biopsy (with videos). Gastrointest Endosc 2018; 88: 919-925

[135] Kasugai H, Yamamoto R, Tatsuta M et al. Value of heparinized fineneedle aspiration biopsy in liver malignancy. AJR Am J Roentgenol 1985; $144: 243-244$ 